\title{
Delamination Buckling of FRP Strips in Strengthened Structural RC Beams and Masonry Walls
}

\author{
E. Magagnini ${ }^{1}$, R. Capozucca ${ }^{1}$, S. Khatir ${ }^{2}$ \\ ${ }^{1}$ DICEA, Structural Section, Polytechnic University of Marche, Italy \\ ${ }^{2}$ Soete Laboratory, Faculty of Engineering and Architecture, University of Gent, Belgium
}

\begin{abstract}
This paper deals with delamination buckling of fibre-reinforced polymer (FRP) strips glued to reinforced concrete (RC) beams or to heterogeneous material as masonry. In the field of rehabilitation of existing civil structures, the strengthening using composite materials is becoming a frequent technique although many points have not yet been clarified. The delamination of FRP strips' layer can be often the cause of loss of the strength capacity in strengthened elements. In general, the delamination is due to loss of adhesion of FRP on the adherent material under tensile loading. This type of delamination foresees a slip of FRP strip and development of fracture energy until the detachment. Delamination buckling of FRP strips is instead due to compression loading. Although the FRP is usually adopted to improve the tensile capacity, in civil structural elements subjected to cycle loading, as RC frames in seismic areas or masonry cross walls, the loading is cyclic and the strengthening of FRP strips may be subjected to compressive stresses with separation of the layer from the adherent element. This type of delamination may significantly influence the strength, stiffness and stability. In this paper experiments on the strengthening of $\mathrm{RC}$ beams and masonry walls with GlassFRP strips are shown;
\end{abstract}

DOI: $10.18421 /$ TEM94-11

https://doi.org/10.18421/TEM94-11

Corresponding author: E. Magagnini,

DICEA, Structural section, Polytechnic University of

Marche, Italy

Email: e.magagnini@univpm.it

Received: 09 October 2020.

Revised: 30 October 2020.

Accepted: 06 November 2020.

Published: 27 November 2020.

(cc) BY-NC-ND(C) 2020 E. Magagnini, R. Capozucca \& S. Khatir; published by UIKTEN. This work is licensed under the Creative Commons Attribution-NonCommercialNoDerivs 4.0 License.

The article is published with Open Access at www.temjournal.com further, analytical and numerical analysis have been developed to study this mechanism of delamination which too often has been missed in the design of strengthening with FRP strips.

Keywords - delamination buckling; FRP; experimental tests; numerical model

\section{Introduction}

The increasing use of composite materials in the field of civil engineering highlights the need to investigate aspects that are not yet completely clear [1-3]. The reliability of the strengthening system made by fiber reinforced polymer (FRP) in RC beams or heterogeneous material as masonry mainly depends on two important factors: the ability of the FRP strengthening to gain the performance of damaged elements re-establishing the ultimate condition under external loading and the preservation of the bond between strengthening and support until failure state.

As pointed out by many researches present in literature, the success of the strengthening systems with composite materials is heavily influenced by the interaction phenomenon born between the reinforcing element and support. The mechanism of failure due to debonding of the FRP glued to different building material can occur, in general, following two different modes: under tensile force as a mechanism of delamination of the FRP strip on masonry/concrete surface and under compression as a mechanism of buckling of the FRP strip.

The delamination by tensile loading is caused by the adhesion loss of the FRP on adherent material foreseeing a slip of the FRP strip and development of fracture energy until the detachment. The works available in literature concern experimental investigation and theoretical/numerical analysis with the purpose to reach a bond behaviour assessment of strengthening system with the FRP under tensile force. For what concerns the experimental characterization, most of the existing work has included experimental studies conducted using single shear tests on concrete [4-8] or masonry [9-13] 
specimens externally strengthened with the FRP applied in the form of strips or sheets. The role of different factors on the debonding mechanism, such as the type of the strengthening system [9], the modalities of application of the strengthening system and its bond length [10], the characteristics of the material composing the substrate [11],[12], the set-up of the experimental apparatus [4],[5],[13] and the influence of the mortar joints in the case of masonry substrates [12] was investigated. Recently, the analysis of damage due to delamination in CFRP composite has been developed also on the base of experimental vibration analysis [14],[15]. In addition, theoretical studies [16-20] and numerical models [2124] were elaborated with the aim to predict the ultimate load, the effective bond length and the entire debonding propagation process in FRP-toconcrete/masonry bounded joints.

Delamination buckling of the FRP layer is instead due to compression loading and it causes separation of the added layer from the main structural element. This mechanism of delamination may significantly influence the strength, stiffness and stability of a strengthened element typical of civil engineering as reinforced concrete/steel/timber beams or masonry. Especially in the field of concrete or masonry structures damage under seismic action, this is an important aspect to be explored. In fact, in these cases, during an earthquake, the FRP strengthening may be subjected to both tensile and compressive stresses. The beginning of delamination buckling in a strengthened element can result from many sources such as defects, deterioration of bending material or local damage due to impact. The delamination buckling of FRP strips in strengthened elements has received the attention of many researchers, that carried out experimental investigations [25-27] and developed analytical models [25], [28-32]. In particular, the experimental campaigns focus the attention on the great influence of mechanical parameters of the substrate [25] and presence of local damage $[26,27]$ in the bond mechanism between GFRP strengthening and concrete/masonry surface under compression. The analytical models present in literature have been concerned with the prediction of the ultimate load and the effective bond length. Most of these deal with an axial loading condition [28-31]; while other concern bending loading relating the transverse external load with the internal axial force [32].

This paper focused on the analysis of delamination buckling of Glass-FRP strips in strengthened structural RC beams and masonry walls. Results of experimental static and dynamic test on the strengthening of RC beams and masonry walls with GFRP strips are analysed. Further, theoretical and numerical analysis have been developed to study this mechanism of delamination.

\section{Experimental Response of RC Beam Strengthened with GFRP}

In the first phase of the experimental campaign, it was chosen to analyze the experimental behavior of a $\mathrm{RC}$ beam undamaged and damaged by cracking of concrete due to bending tests considering the presence of strengthening with NSM GFRP rod and externally bonded (EB) GFRP strip in the compressed side. The experimental model was studied under static and free vibration tests [33]. The geometry of the beam model is characterized by dimensions of section equal to $120 \mathrm{~mm} \cdot 160 \mathrm{~mm}$ and length equal to $2.20 \mathrm{~m}$. The reinforcements were made by four rods with a diameter of $10 \mathrm{~mm}$ placed at each extremity of section and stirrups with a diameter of $6 \mathrm{~mm}$. In addition, a groove measuring $20 \mathrm{~mm} \cdot 20 \mathrm{~mm}$ was realized in the concrete cover at intrados in order to insert the GFRP rod and glued it to the concrete using epoxy adhesive [18]. The mechanical properties of materials were experimentally evaluated and the following results were obtained: for concrete, tested average cylinder strength equals to $f_{c, a v} \approx 44 \mathrm{~N} / \mathrm{mm}^{2}$ and Young's modulus $E_{c} \approx 35.0 \cdot 10^{3} \mathrm{~N} / \mathrm{mm}^{2}$; for steel bars, average yielding stress equals to $f_{y, a v} \approx 500 \quad \mathrm{~N} / \mathrm{mm}^{2}$ and Young's modulus $E_{s}=2.1 \cdot 10^{5} \mathrm{~N} / \mathrm{mm}^{2}$. Tensile tests were performed on GFRP specimens according to the ASTM-D 3039 Standard [34] with the aim to determine the geometric and mechanical parameters of the GFRP rod and strip utilized as strengthening during tests. The RC beam was statically tested until failure, considering three different configurations of the strengthening. Results of static tests are summarized in Table 1.

Table 1. Experimental geometrical/mechanical parameters of the GFRP rod/strip

\begin{tabular}{|c|c|c|c|c|c|c|c|}
\hline \multicolumn{3}{|c}{} & \multicolumn{4}{c|}{ GFRP strip } \\
\hline $\begin{array}{c}\text { Diameter } \\
\boldsymbol{d}_{\text {GFRP }} \\
{[\mathbf{m m}]}\end{array}$ & $\begin{array}{c}\text { Section area } \\
A_{G F R P} \\
{\left[\mathrm{~mm}^{2}\right]}\end{array}$ & $\begin{array}{c}\text { Tensile strength } \\
f_{G F R P} \\
{\left[\mathrm{~N} / \mathrm{mm}^{2}\right]}\end{array}$ & $\begin{array}{c}\text { Young's } \\
\text { modulus } \\
E_{G F R P} \\
{\left[\mathrm{kN} / \mathrm{mm}^{2}\right]}\end{array}$ & $\begin{array}{c}\text { Equivalent } \\
\text { thickness } \\
t_{f} \\
{[\mathrm{~mm}]}\end{array}$ & $\begin{array}{c}\text { Equivalent } \\
\text { thickness } \\
t_{f} \\
{[\mathrm{~mm}]}\end{array}$ & $\begin{array}{c}\text { Equivalent } \\
\text { thickness } \\
t_{f} \\
{[\mathrm{~mm}]}\end{array}$ & $\begin{array}{c}\text { Equivalent } \\
\text { thickness } \\
t_{f} \\
{[\mathrm{~mm}]}\end{array}$ \\
\hline $\mathbf{9 . 5 2}$ & 71.26 & 1040 & 33.6 & 0.12 & 0.12 & 0.12 & 0.12 \\
\hline
\end{tabular}


Table 2. Exp. results for RC beam with and without strengthening at different loading steps

\begin{tabular}{|c|c|c|c|c|c|c|}
\hline $\begin{array}{c}\text { Load } \\
P \\
{[\mathrm{kN}]}\end{array}$ & $\begin{array}{c}\text { Deflection } \\
d \\
{[\mathrm{~mm}]}\end{array}$ & $\begin{array}{c}\text { Strain at } \\
\text { compressive } \\
\text { concrete } \\
\varepsilon_{c}\left(1^{-3}\right)\end{array}$ & $\begin{array}{c}\text { Strain at } \\
\text { steel } \\
\text { (intrados) } \\
\varepsilon_{s}\left(1^{-6}\right)\end{array}$ & $\begin{array}{c}\text { Strain at } \\
\text { GFRP rod } \\
\varepsilon_{G F R P, \text { rod }} \\
\left(10^{-6}\right)\end{array}$ & $\begin{array}{c}\text { Strain at } \\
\text { GFRP strip } \\
\mathcal{E}_{G F R P, \text { strip }} \\
\left(1^{-6}\right)\end{array}$ & $\begin{array}{c}\text { Curvature } \\
\left.\qquad \mathrm{mm}^{-1} \cdot \mathbf{1 0}^{-5}\right]\end{array}$ \\
\hline \multicolumn{7}{|c|}{ RC beam without strengthening } \\
\hline 4.00 & 1.40 & -225.12 & 646.32 & - & - & 0.65 \\
\hline 8.00 & 4.56 & -455.35 & 1450.66 & - & - & 1.50 \\
\hline 18.00 & 10.88 & -298.85 & 3357.96 & - & - & 3.30 \\
\hline \multicolumn{7}{|c|}{ RC beam with NSM GFRP rod } \\
\hline 4.00 & 1.63 & -169.20 & 459.60 & 290.88 & - & 0.31 \\
\hline 8.00 & 3.75 & -379.18 & 1036.09 & 663.72 & - & 0.70 \\
\hline 16.00 & 7.54 & -769.80 & 2125.40 & 1472.54 & - & 1.49 \\
\hline 28.00 & 17.46 & -1977.03 & 5605.48 & 6080.50 & - & 5.37 \\
\hline \multicolumn{7}{|c|}{ RC beam with NSM GFRP rod and EB GFRP strips } \\
\hline 4.00 & 1.95 & -220.80 & - & 532.80 & -134.88 & 0.50 \\
\hline 8.00 & 3.98 & -453.37 & - & 1048.66 & -278.26 & 1.00 \\
\hline 16.00 & 8.36 & -971.61 & - & 2201.20 & -589.29 & 2.12 \\
\hline 20.00 & 10.62 & -1231.29 & - & 2770.56 & -736.61 & 2.67 \\
\hline 28.00 & 16.71 & -2008.59 & - & 8079.64 & -1118.00 & 6.73 \\
\hline $\begin{array}{c}33.48 \\
\text { (Failure) }\end{array}$ & 53.61 & -3038.16 & - & - & -4438.60 & 10.4 \\
\hline
\end{tabular}

Initially, static tests were performed on the beam without any strengthening by bending loading path, with an increasing vertical load $\mathrm{P}$ applied at two points, $300 \mathrm{~mm}$ from the middle of the beam. Cyclic increasing loads $\mathrm{P} 1=4.0 \mathrm{kN}, \mathrm{P} 2=8.0 \mathrm{kN}, \mathrm{P} 3=18.0 \mathrm{kN}$ were chosen with the purpose to damage beam B1 with cracks avoiding the yield of steel reinforcement. The set-up of static tests involved the use of the following instruments: a vertical jack to transmit the load P with a load cell to measure P; strain gauges on the surface of a steel rod at the intrados and compressive concrete at the extrados to measure the evolution of deformation during bending tests; two LVDTs to measure deflection at the mid span section and close to the support.

After the first phase of bending tests, the beam has been strengthened with a GFRP rod inserted into the rectangular notch made previously following the NSM technique. The GFRP rod was glued to the concrete cover using an epoxy adhesive characterized by the following mechanical properties: Young's modulus $E_{\text {res }}=1600 \mathrm{~N} / \mathrm{mm}^{2}$ and Poisson's modulus $v \approx 0.48$, obtained by compression tests on two specimens. The static bending test on the beam with NSM GFRP rod was carried out adopting four cycles of loading with maximum load steps corresponding to the damage levels $\mathrm{Di}$ with $\mathrm{i}=1, \ldots, 4$ equal to $\mathrm{P}=4 \mathrm{kN}$ - damage degree $\mathrm{D} 1 ; \mathrm{P}=8 \mathrm{kN}-\mathrm{D} 2 ; \mathrm{P}=16 \mathrm{kN}$ - D3; $\mathrm{P}=28 \mathrm{kN}-\mathrm{D} 4$. Finally, the same beam was also strengthened with two GFRP strips externally glued on the top of the lateral surface of section as shown in Fig. 1.(a) to check the reliability of strengthening in the compressive zone and to observe the possible local mechanism of delamination buckling that is typical in slender element, as EB FRP strips, under compression. The beam model was once again subjected to the same loading path $\mathrm{P}=4 \mathrm{kN}$ - damage degree $\mathrm{D} 1 ; \mathrm{P}=8 \mathrm{kN}-\mathrm{D} 2 ; \mathrm{P}=16 \mathrm{kN}-\mathrm{D} 3 ; \mathrm{P}=28 \mathrm{kN}-$ D4 and, successively, tested until failure. Two strain gauges were applied on the surface of GFRP strips in both sides in order to monitor the evolution of strains during tests (Fig. 1.(b)).

For the tested model, collapse was reached for a load equal to $33.48 \mathrm{kN}$. The detail of damage at failure is shown in Fig. 2. where we can also witness the effect of delamination buckling which occurred following the compressive failure of concrete at the top of the beam's midspan zone. The strain values measured on the compressed concrete, on the GFRP rod and the GFRP strip, $\varepsilon_{c}, \varepsilon_{G F R \text {,rod }}$ and $\varepsilon_{G F R \text {,strip }}$, are contained in Table 2. for all damage degrees. It is noted that the maximum value of strain on the compressed GFRP strip reached a high value of deformation equal to about $1.1 \cdot 10^{-3}$, before the detachment due to delamination buckling. The delamination buckling of the composite strips occurred only after the crash of the compressed concrete, so the bond between the EB GFRP strips and concrete is maintained and the deformation of concrete is followed up to the collapse. 

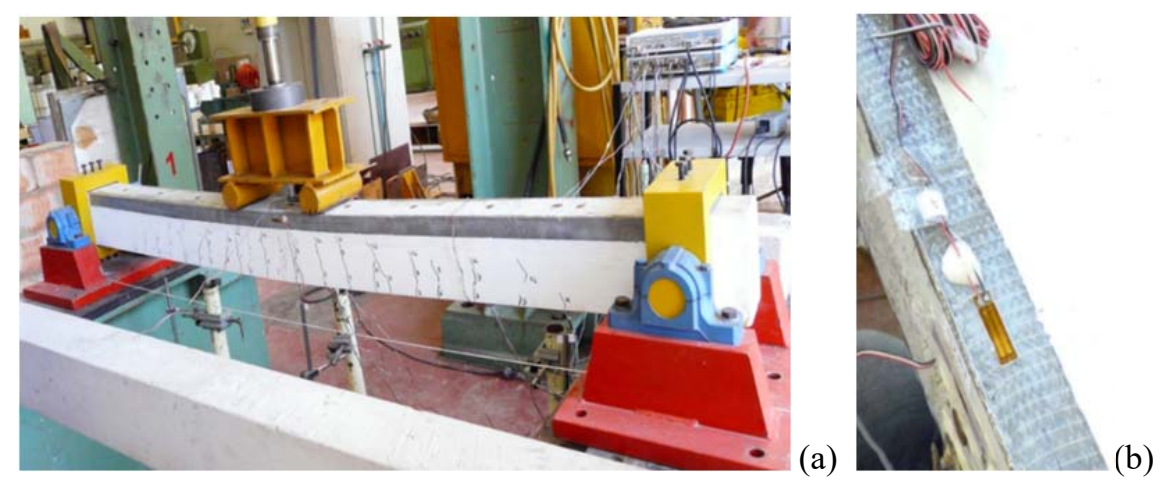

Figure 1. (a) Set up of bending test for RC beam strengthened with NSM GFRP and EB GFRP; (b) strain gauges applied on the surface of GFRP strip

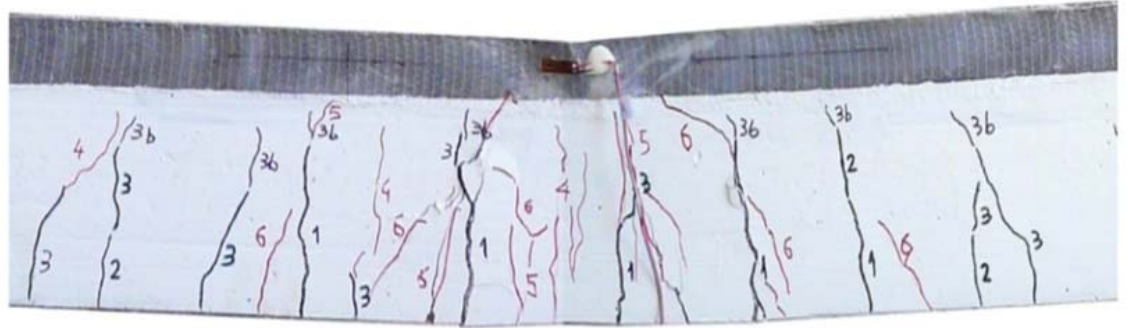

(a)

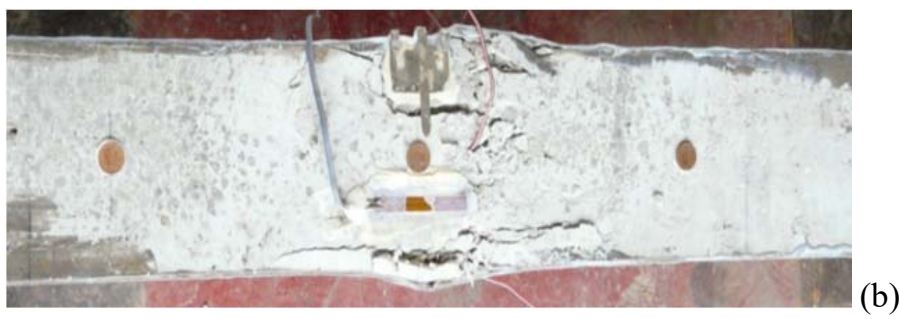

Figure 2. (a) Failure of RC beam strengthened with EB GFRP strip and detail of damage with the effect of delamination buckling; (b) view of the extrados of the damaged beam

Figure 3, shows a comparison between the experimental diagrams moment, $\mathrm{M}$, versus curvature, $\chi$, evaluated for the RC beam both with NSM GFRP strengthening and EB GFRP strips. It can be noticed how the strengthening with externally glued GFRP strips equipped $\mathrm{RC}$ beam led to a strong increase in curvature. The increase in resistance is low, due mainly to the mechanism of damage that interests the GFRP strips that may be considered as delamination buckling under compressive stresses. The unstrengthened and strengthened RC beam was dynamically examined by free vibration tests at each step of loading Di. Modal testing was carried out on the RC beam adopting the hinged ends as simply supported beam. The dynamic test was performed exciting the structure in a fixed position with an impact hammer and recording the response of the structure in 9 positions as marki $i=1, \ldots, 9$, with an average of 10 beats per location. Frequency values were extracted by transformed signals in the frequency domain through the FFT technique using Pulse software in a range between 0 and $1500 \mathrm{~Hz}$. In order to evaluate the reliability of the measurements, a function referred to as coherence was considered [33].

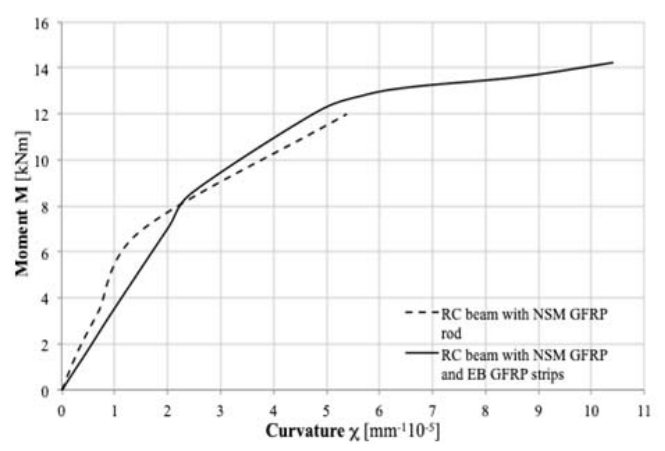

Figure 3. Comparison between experimental diagrams moment, $M$, vs curvature, $\chi$, for the different configuration of GFRP strengthening

\section{Historic Brickwork Masonry Strengthened with GFRP Strips}

The delamination buckling can interest also EB GFRP strips glued to heterogeneous material as masonry. In fact, frequently GFRP strips are adopted to strengthen damage masonry walls cracked by seismic actions.

The experimental campaign was performed on masonry walls made by clay bricks in scale $1 / 3$ rd [35] obtained from historic full-scale handmade 
bricks. Static tests were carried out on two models labelled as W1 and W2. The masonry walls were tested under combined compression and shear force as described below [26]. The wall $W 1$ was initially tested without strengthening; the model W2 was, instead, strengthened by GFRP strips just before cyclic shear tests. After damage due to diagonal cracking, wall $\mathrm{W} 1$ has been provided by the strengthening with GFRP strips in the same way of W2.

The specimens were realized by a cement: lime: sand (1:1:5) mortar by volume. The average compressive strength of the clay bricks was $f_{b}=27.8 \mathrm{~N} / \mathrm{mm}^{2}$. The mortar was characterized by the following values of strength: average compressive strength $f_{m}=3.56 \mathrm{~N} / \mathrm{mm}^{2}$ and bending tensile strength $f_{m t}=1.80 \mathrm{~N} / \mathrm{mm}^{2}$. A set of preliminary tests were performed on brickwork walletts of $200 \mathrm{~mm} \times$ $200 \mathrm{~mm}$ in plane and thickness of $50 \mathrm{~mm}$, that were tested under compression until failure. The obtained average compressive strength was $f_{w} \approx 13.5 \mathrm{~N} / \mathrm{mm}^{2}$ with Young's modulus of elasticity, $E_{w}=8550 \mathrm{~N} / \mathrm{mm}^{2}$ and Poisson ratio $v=0.20$.

The dimensions of the tested wall models are $633.635 .50 \mathrm{~mm}$. All the specimens have been subjected to the same pre-compression normal stress equal to $\sigma_{v}=1.2 \mathrm{~N} / \mathrm{mm}^{2}$, kept constant during the cyclic shear loading. Vertical load was applied to the wall through load distribution's systems made by a steel slab positioned on the top of the model (Fig. 4.). The evolution of the principal strains in the center of
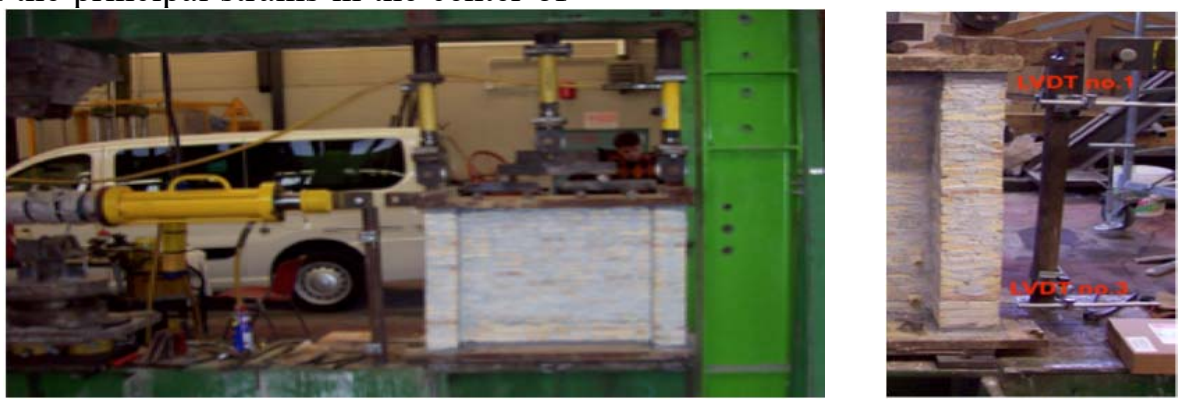

Figure 4. Set-up of compression-shear tests on brickwork historic masonry walls

Table 3. Horizontal load, F, vs horizontal displacements evaluated by LVDTs for wall U-W1

\begin{tabular}{cccc}
\hline Lateral & \multicolumn{3}{c}{ Horizontal displacements $(\mathrm{mm})$} \\
\cline { 2 - 4 } Load $(\mathrm{kN})$ & 1 & 2 & 3 \\
-5 & -0.01875 & 0.08438 & 0 \\
5 & -0.003125 & 0.02813 & 0 \\
10 & -0.14688 & 0.19063 & -0.0125 \\
-10 & 0.01875 & -0.02813 & 0.00313 \\
30 & -0.27186 & 0.33125 & -0.01563 \\
-30 & 0.25625 & -0.3125 & 0.03125 \\
40 & -0.40938 & 0.49063 & -0.025 \\
-40 & 0.4 & -0.475 & 0.04375 \\
45 & -0.721875 & 0.8375 & -0.040625 \\
-50 & 0.703125 & -0.821875 & 0.071875 \\
55 & -1.3875 & 1.58125 & -0.0625 \\
-50 & 0.703125 & -0.809375 & 0.078125 \\
60 & -2.19063 & 2.46563 & -0.06875 \\
62.1 & -3.00938 & 3.39063 & -0.0875 \\
\hline
\end{tabular}


In addition to all instruments used for the test on the unreinforced wall, strain gauges were applied along the composite's surface in order to value axial strains along the strengthening strip. For these measures, strain gauges of type LY11-10/120 with a nominal resistance of $120 \Omega$ were adopted (Fig. 5.(b)).

The test was carried out on DR-W1 with the same procedure adopted for the test on the unreinforced wall. The wall reached failure for the delamination of the GFRP fibers with debonding of the diagonal strips due to tension at the 16th cycle of loading at a horizontal load value of approximately $F=92.2 \mathrm{kN}$. Shear test on the W2 model undamaged and strengthened (R-W2) with the GFRP strips on one side was carried out using the same methodology and with the same loading path as the DR-W1 model. Eleven complete loading cycles were applied. The test was carried out up to horizontal force value equal to about $F=45 \mathrm{kN}$ and $d=8 \mathrm{~mm}$. Table 4 . contains the maximum lateral displacements recorded by LVDTs no.1, 2 and 3 for all cycles. The collapse of R-W2 wall model has been assumed at value of horizontal load equal about $F \cong-55 \mathrm{kN}$ with complete detachment of the GFRP strip due to compression and displacement of the flange with damage of masonry. In this case, after the diagonal cracking, when the tensile capacity of masonry has been increased, detachment of the GFRP strips happened close to the top and the bottom of the wall with cracks on the mortar joints of flange.

The loss of adhesion of the strengthening system on the masonry support happened closed to point of strain gauge E6 with a mechanism of delamination due to compression (Fig. 6.). The horizontal forces, $\mathrm{F}$, with double versus determine alternatively both tensile and compression stresses in the masonry web and EB GFRP strengthening. Although masonry can carry out main part of compressive force for his greater thickness, also the GFRP strip is subjected to a part of compression. Local cracking mechanism can negatively affect the bond behavior between GFRP strengthening and masonry surface, causing possible phenomena of brittle failure.
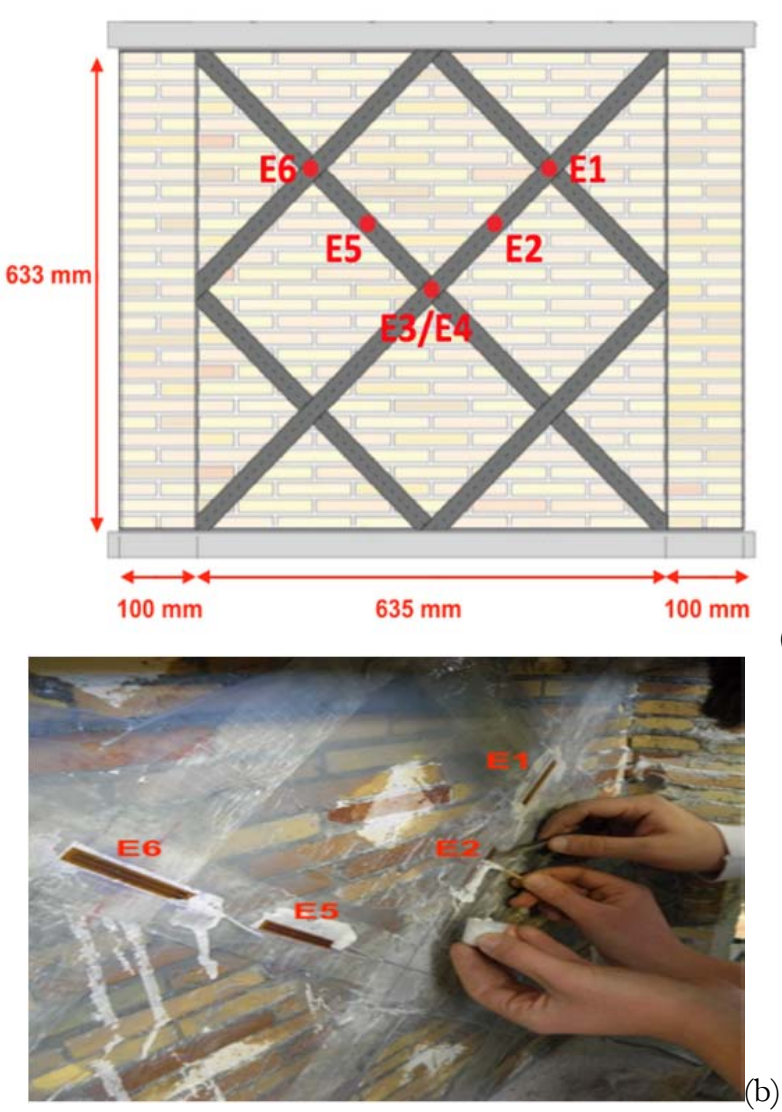

(a)

Figure 5. (a) Position of the strain gauges E1,..,E6 along the GFRP strip diagonals in R-W2 specimen; (b) application of the strain gauges on the GFRP surface

Table 4. Horizontal load, F, vs horizontal displacements evaluated by LVDTs for wall R-W2

\begin{tabular}{|c|c|c|c|}
\hline \multirow{2}{*}{$\begin{array}{c}\text { Lateral } \\
\text { Load } \\
\mathbf{( k N})\end{array}$} & \multicolumn{3}{|c|}{ Horizontal displacements $(\mathbf{m m})$} \\
\cline { 2 - 4 } & 1 & 2 & 3 \\
\hline $\mathbf{- 5}$ & 0.084 & -0.059 & 0.025 \\
\hline $\mathbf{5}$ & -0.025 & 0.075 & 0.019 \\
\hline $\mathbf{- 1 0}$ & 0.228 & -0.169 & 0.056 \\
\hline $\mathbf{1 0}$ & -0.134 & 0.169 & 0.013 \\
\hline $\mathbf{- 1 2 . 5}$ & 0.288 & -0.213 & 0.075 \\
\hline $\mathbf{1 2 . 5}$ & -0.203 & 0.216 & -0.006 \\
\hline $\mathbf{- 1 5}$ & 0.35 & -0.263 & 0.088 \\
\hline $\mathbf{1 5}$ & -0.266 & 0.259 & -0.019 \\
\hline $\mathbf{2 0}$ & -0.422 & 0.363 & -0.05 \\
\hline $\mathbf{- 3 0}$ & 0.978 & -0.781 & 0.225 \\
\hline $\mathbf{3 0}$ & -0.763 & 0.638 & -0.106 \\
\hline $\mathbf{4 0}$ & 1.725 & -1.416 & 0.381 \\
\hline $\mathbf{4 0}$ & -1.347 & 1.172 & -0.156 \\
\hline $\mathbf{5 0}$ & 2.963 & -2.447 & 0.613 \\
\hline $\mathbf{4 5}$ & -3.747 & 3.769 & -0.019 \\
\hline $\mathbf{5 5}$ & 5.716 & -4.475 & 1.219 \\
\hline $\mathbf{4 5}$ & -5.156 & 5.913 & 0.25 \\
\hline $\mathbf{4 0}$ & -7.856 & 8.584 & 0.206 \\
\hline & & & \\
\hline
\end{tabular}


Figure 7. contains the evolution of strains recorded for each load cycle in the function of the horizontal load and evaluated at the position of strain gauges E5 and E6. It is possible to observe that the strain's values registered by the strain gauges are essentially null for the first load cycles, up to a shear loading $\mathrm{F} \approx 30 \div 40 \mathrm{kN}$, equal to the cracking load of masonry. After this limit, the value of strains increases quickly for both positions of strain gauges and the shear capacity depends mostly by the tensile strength of GFRP strips that give also a contribution in limiting the width of cracks. This aspect confirms the great influence of mechanic parameters on the response of historic walls strengthened with EB GFRP strips under loading. In the case of historical brickwork masonry, the local cracking development can cause both local debonding mechanisms of tensile GFRP strips and buckling delamination.
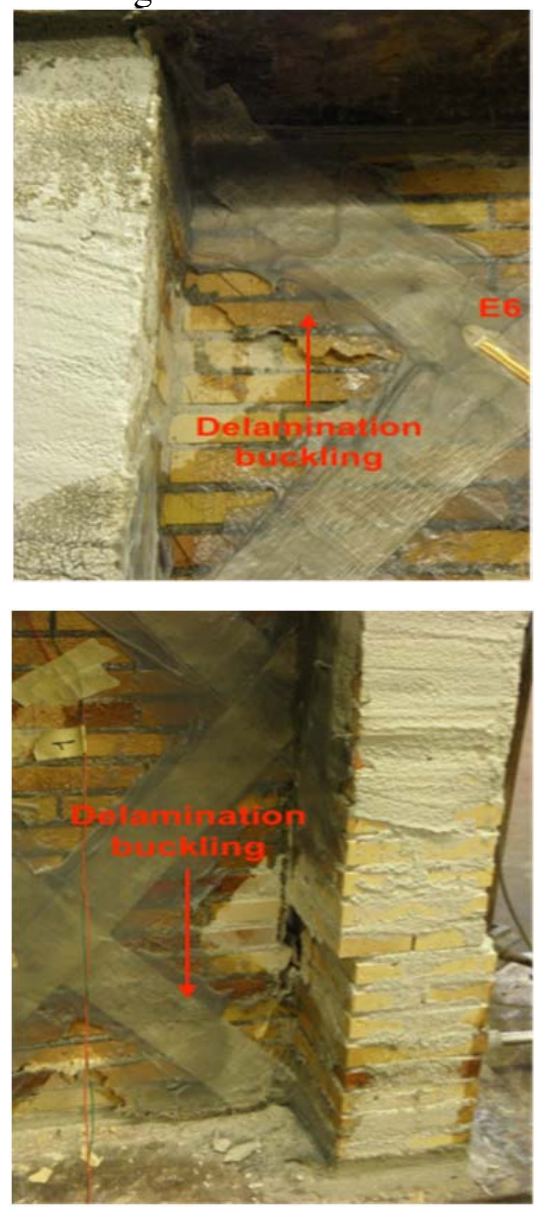

Figure 6. Collapse of $R-W 2$ wall with detail of delamination buckling along the diagonal of the GFRP strip
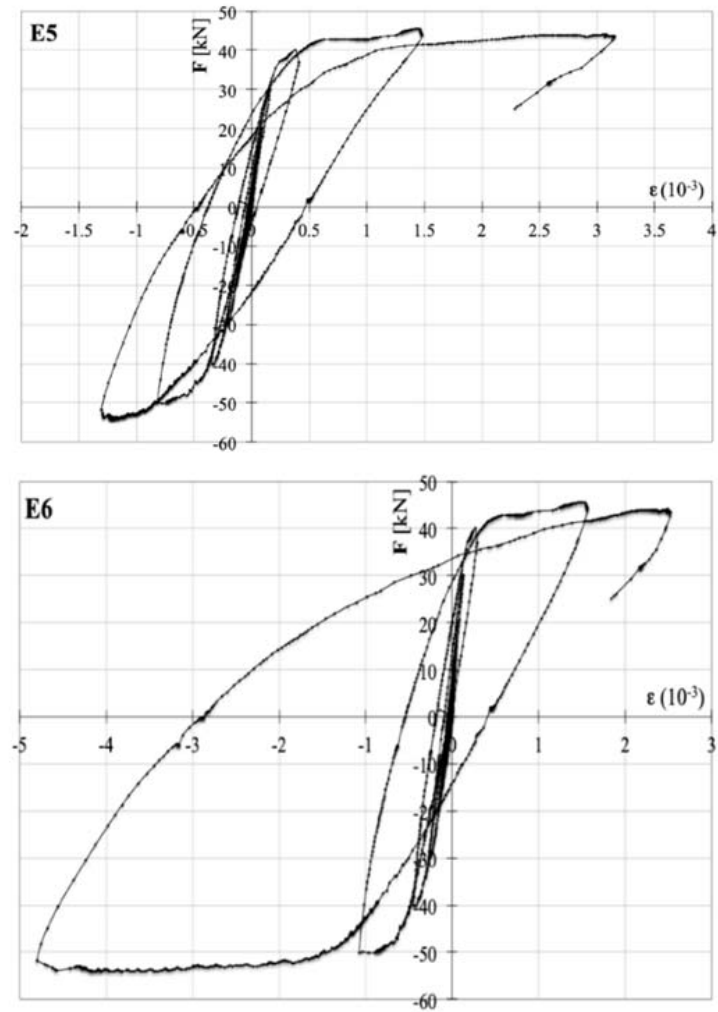

Figure 7. Experimental diagrams load, $F$, vs strain values measured on strain gauges E5 and E6 glued on diagonal GFRP strip for strengthened wall R-W2

\section{Analytical Model for Delamination Buckling}

As already described above, delamination buckling can become sometimes the main damage mechanism for the strengthening bonded to historic masonry surface.

The analysis of delamination buckling of FRP strip has been developed below using a simplified elastic model where all materials are considered as linear; the plane sections remain plane after delamination buckling and the bond between adhesive and FRP strip remains up to a displacement of the FRP due to delamination buckling [25]. In Fig. 8. the deflection of compressed FRP strip is shown considering the presence of a plane adhesive layer. The FRP strip is assumed as an elastic beam hinged at the ends, glued to the adhesive layer, of unknown length 1 . The interfacial normal stress along the adhesive can be expressed as follows:

$$
\sigma_{n}(x)=k_{n} \cdot w_{a}(x)
$$

where $k_{n}$ is the normal stiffness of the adhesive on the unit length that can be expressed as: 


$$
k_{n}(x)=\frac{\sigma_{n}(x)}{w_{a}(x)}=\frac{\sigma_{n}(x)}{w_{a}(x) \cdot t_{a}} \cdot \frac{1}{t_{a}}=\frac{E_{a}}{t_{a}}
$$

being

$$
w_{a}(x)=w_{2}(x)
$$

with $w_{a}(x)$ the normal displacement between the interface FRP strip and adhesive.

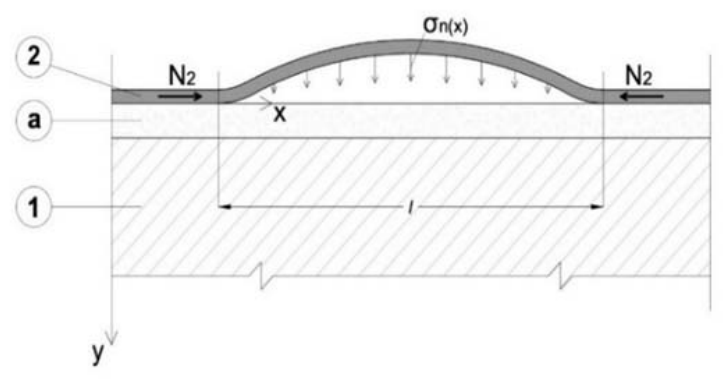

Figure 8. Delamination buckling of FRP strips under compression

Assuming that the elastic constant $k_{0}$ is the value $k_{0}$ $=k_{n} \cdot b$, being $b$ the width of the FRP, the distribution of normal load on unit length may be written as:

$$
p(x)=\left(k_{n} \cdot b\right) \cdot w_{2}(x)
$$

On the basis of principal work, it is possible to write:

$$
\frac{N_{2}}{2} \cdot \int w_{2}^{\prime}(x) d x=\frac{1}{2} \int K_{0} w_{2}^{2}(x) d x+\frac{1}{2} \int E_{2} I_{2} w_{2}^{\prime \prime}(x) d x
$$

Following Rayleigh's procedure [14], it is possible to assume this function $w_{2}(x)$ :

$$
w_{2}(x)=w_{0} \sin \pi \frac{x}{l}
$$

Then we can substitute it in Eq. (5) and solve for $N_{2}$ which is the critical buckling load for delamination buckling; in fact only when $N_{2}=P_{E, F R P}$ the FRP strip is in equilibrium for deflected shape. We obtain:

$$
\begin{aligned}
& \frac{N_{2}}{2} \cdot \int_{0}^{l} w_{0}(x) \cdot \frac{\pi}{l} \cdot \cos ^{2} \frac{\pi x}{l} d x=\frac{1}{2} k_{0} \int w_{2}^{2}(x) d x \\
& +\frac{1}{2} E_{2} I_{2} \int\left(w_{0} \cdot \frac{\pi^{2}}{l^{2}}\right)^{2} \sin ^{2} \frac{\pi x}{l} d x
\end{aligned}
$$

The final expression may be obtained in Eq. (7) both integrals square sines and cosines whose value is half the length $l / 2$ :

$$
\begin{aligned}
& \frac{N_{2}}{2} \cdot\left(\frac{\pi}{l}\right)^{2} \cdot w_{0}^{2} \cdot \frac{I}{2}=\frac{1}{2} k_{0} \cdot w_{0}^{2} \cdot \frac{I}{2} \\
& +\frac{1}{2} E_{2} I_{2} \cdot\left(\frac{\pi}{4}\right)^{4} \cdot w_{0}^{2} \cdot \frac{I}{2}
\end{aligned}
$$

and

$$
P_{E, F R P}=k_{0} \cdot\left(\frac{l}{\pi}\right)^{2}+E_{2} I_{2} \cdot\left(\frac{\pi}{l}\right)^{2}
$$

The Eq. (9) says that, in this case, $P_{E, F R P}$ is greater than the Euler load which is augmented of $k_{0} \cdot\left(\frac{l}{\pi}\right)^{2}$ due to the presence of the adhesive layer. Assuming $\beta=\sqrt[4]{\frac{k_{0}}{4 E_{2} I_{2}}}$, it is possible to write:

$$
\frac{P_{E, F R P}}{\sqrt{k_{0} E_{2} I_{2}}}=t^{2}+\left(\frac{1}{t}\right)^{2}
$$

with

$$
t=\frac{\sqrt{2}}{\pi} \cdot \beta \cdot l
$$

for $t=1$

$$
P_{E, F R P}=2 \cdot \sqrt{k_{0} E_{2} I_{2}}
$$

which is the smallest load of delamination buckling for any length $l$.

By experimental test on R-W2 wall model, it is possible to estimate the value of $P_{c r}$ and the value of constant k. Strain values of the GFRP strip on compressive principal diagonal at the beginning of delamination process for horizontal force $\mathrm{F} \approx-55 \mathrm{kN}$ may be assumed as $\varepsilon_{\text {max }} \approx 1 \cdot 10^{-3}$. So that the $P_{c r}$ of the GFRP strip may be estimated about $3200 \mathrm{~N}$ with $A_{G F R P}$ area of section equal to $50 \mathrm{~mm}^{2}$. Knowing the value of $P_{c r}$ and inserting it in Eq. (12), we obtain the constant equal to about $k \approx 9.6 \mathrm{~N} / \mathrm{mm}^{2}$ that it is representative of ideal spring's modulus.

\section{Analysis of Bond by FE Modeling}

The results of the experimental campaign described above point out how the mechanisms of adhesion between the GFRP strips and the masonry support are influenced by the property of each material and the cracking behaviour of brickwork.

Theoretical analysis with modeling by FE has been developed using ANSYS code to analyze the behaviour of strengthened wall model R- W2 under shear loading and to compare experimental results of strain measured on the GFRP strips at E1,..,E6 with numerical data. A macro-modelling approach together with a non-linear static analysis has been developed (Fig. 9.). The historic masonry wall's assemblage has been modeled with the employment of the solid brick element, called Solid65, characterized by eight nodes having three degrees of freedom at each node and the capability of crushing in compression and cracking in tension. A combination of constitutive laws, that is the DruckerPrager plasticity material model together with 
William-Warnke failure surface, has been used to properly reproduce the behaviour of masonry [36]. For what concerns the strengthening system, the GFRP strips are modeled using truss elements (Link 180) directly connected to the nodes of the mesh of the panels, imposing a perfect adhesion between the nodes of trusses and the corresponding nodes of the mesh of the panels.
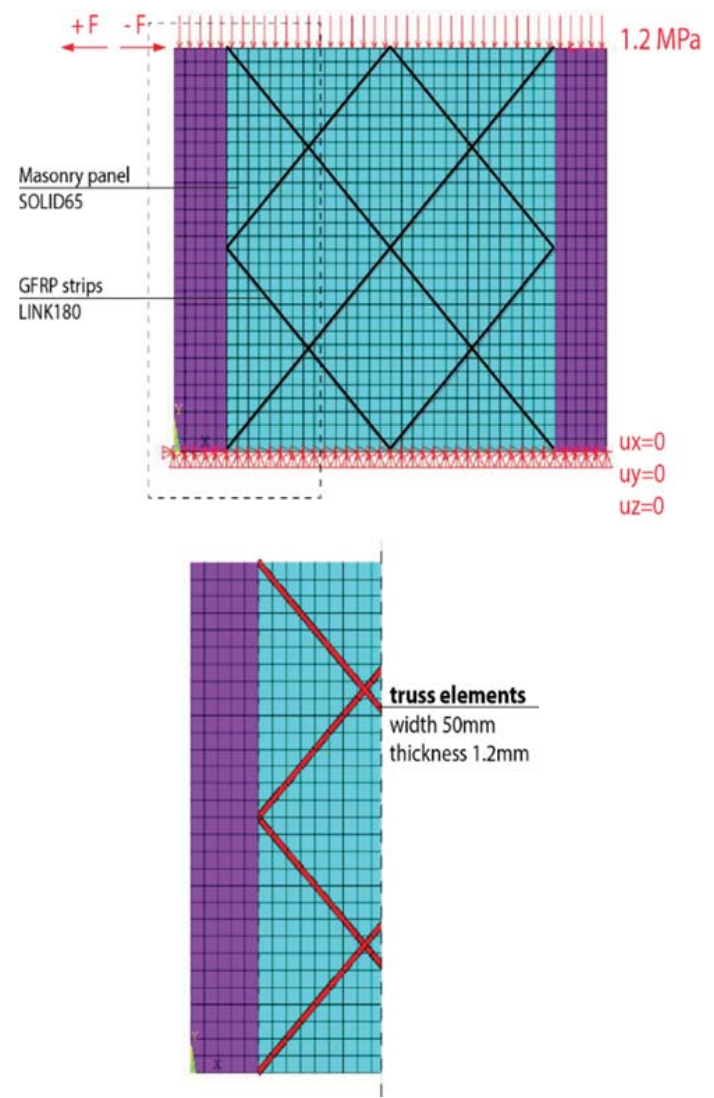

Figure 9. FE tridimensional model of R-W2 wall

To simulate the mechanical behaviour of the GFRP strengthening and the interaction between masonry/FRP elements, the mechanical parameters adopted for GFRP strips were defined through a simplified approach assuming a special constitutive law for truss elements and considering the reinforcement perfectly glued to the masonry support [37]. An elastic-brittle behaviour has been considered by assigning an elastic stiffness value equal to Young's modulus of the GFRP strengthening and different values for the strength of the FRP elements. In particular, the maximum strength of FRP elements, linked to the bond length, $l_{b}$, of each element, has been evaluated according to the relations proposed by the Italian Code of CNR [38]:

$$
\begin{aligned}
& f_{f d d}=\frac{1}{\gamma_{f d} \sqrt{\gamma_{m}}} \sqrt{\frac{2 E_{F R P} \Gamma_{F K}}{t_{F R P}}} \quad \text { if } l_{b} \geq l_{e} \\
& f_{f d d, r i d}=f_{f d d} \frac{l_{b}}{l_{e}}\left(2-\frac{l_{b}}{l_{e}}\right) \text { if } l_{b}<l_{e}
\end{aligned}
$$

$$
l_{e}=\sqrt{\frac{E_{F R P} \cdot t_{F R P}}{2 \cdot f_{w t}}}
$$

where $\gamma_{\mathrm{fd}}$ is a factor that takes into account the modality of the application of the reinforcement system; $\gamma_{m}$ is the partial safety factor for masonry material [39], assumed to be equal to 1.0 for obtaining the characteristic value of bond strength; $l_{e}$ is the optimal bond length of the FRP corresponding to the minimal bond length able to carry the maximum anchorage force and $l_{b}$ is the effective bond length. The fracture energy value has been derived from the results of pull-push shear tests on bonded GFRP-to-historic brickwork masonry wallets [12] and it was assumed equal to $0.375 \mathrm{~N} / \mathrm{mm}$.

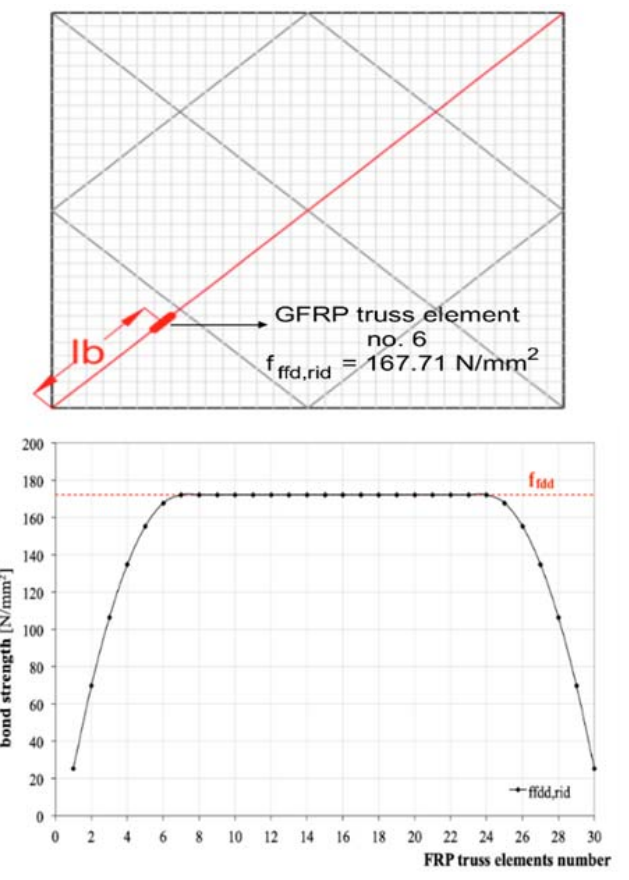

Figure 10. Evaluation of the bond strength along with each element of the GFRP diagonal

In Fig. 10. the values of the bond strength evaluated for each FRP element number, for one diagonal, have been depicted. The identification of $f_{\text {fdd }}$ is fundamental because it represents the parameter strictly related to the adhesion mechanisms between reinforcement and masonry. The accuracy of the numerical results obtained using macro-modelling approach has been assessed through a comparison of experimental and theoretical strain values along the GFRP strips. Fig. 11. contains the maximum strain recorded for each load cycle for R-W2 wall model in function of the horizontal load, $\mathrm{F}$, at the position of strain gauges, E1, ..., E6, compared with the theoretical axial strains evaluated by FEM. It is possible to observe that the proposed simplified approach assuming an elastic-brittle behavior of the GFRP strips, allows obtaining a good estimate of the axial deformations, in agreement with what emerged from the experimental campaign. 

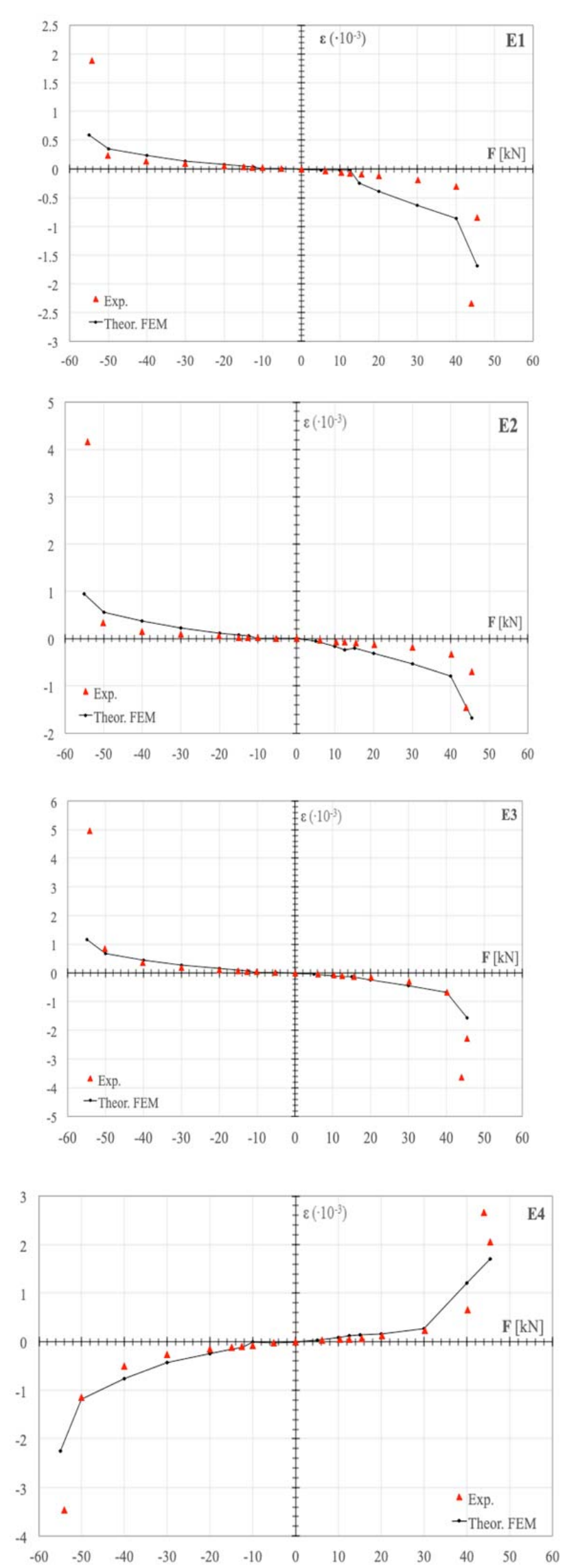


\section{Acknowledge}

The Authors wish to thank all the technicians and students who worked to carry out the experimental tests. The experimental research was developed through funds provided by Polytechnic University of Marche, Italy.

\section{References}

[1]. Mansouri, L., Djebbar, A., Khatir, S., Ali, H. T., Behtani, A., \& Wahab, M. A. (2019). Static and fatigue behaviors of short glass fiber-reinforced polypropylene composites aged in a wet environment. Journal of Composite Materials, 53(25), 3629-3647.

[2]. Mansouri, L., Djebbar, A., Khatir, S., \& Wahab, M. A. (2019). Effect of hygrothermal aging in distilled and saline water on the mechanical behaviour of mixed short fibre/woven composites. Composite Structures, 207, 816-825.

[3]. Capozucca, R., \& Cerri, M. N. (2002). Static and dynamic behaviour of RC beam model strengthened by CFRP-sheets. Construction and Building Materials, 16(2), 91-99.

[4]. Yao, J., Teng, J. G., \& Chen, J. F. (2005). Experimental study on FRP-to-concrete bonded joints. Composites Part B: Engineering, 36(2), 99113.

[5]. Bizindavyi, L., \& Neale, K. W. (1999). Transfer lengths and bond strengths for composites bonded to concrete. Journal of composites for construction, 3(4), 153-160.

[6]. Täljsten, B. (1997). Defining anchor lengths of steel and CFRP plates bonded to concrete. International Journal of adhesion and adhesives, 17(4), 319-327.

[7]. Capozucca, R. (2013). Analysis of bond-slip effects in RC beams strengthened with NSM CFRP rods. Composite Structures, 102, 110-123.

[8]. Capozucca, R. (2014). On the strengthening of RC beams with near surface mounted GFRP rods. Composite Structures, 117, 143-155.

[9]. Capozucca, R. (2010). Experimental FRP/SRPhistoric masonry delamination. Composite structures, 92(4), 891-903.

[10]. Grande, E., Imbimbo, M., \& Sacco, E. (2011). Bond behaviour of CFRP laminates glued on clay bricks: experimental and numerical study. Composites Part B: Engineering, 42(2), 330-340.

[11]. Aiello, M. A., \& Sciolti, M. S. (2003). Masonry structures strengthened with FRP sheets: experimental investigation of bond between FRP laminates and ashlars. Internationale Zeitschrift für Bauinstandsetzen und Baudenkmalpflege $=$ International journal for restoration of buildings and monuments, 9(6), 639-662.

[12]. Capozucca, R., \& Ricci, V. (2016). Bond of GFRP strips on modern and historic brickwork masonry. Composite Structures, 140, 540-555.

[13]. Briccoli Bati, S., Rotunno, T., Rovero, L., \& Tonietti, U. (2006, August). Experimental study on CFRP-brick bonded joints. In Proceedings of Fourteenth International Conference on Mechanics of Composite Materials.
[14]. Capozucca, R. (2013). A reflection on the application of vibration tests for the assessment of cracking in $\mathrm{PRC} / \mathrm{RC}$ beams. Engineering structures, 48, 508-518.

[15]. Samir, K., Brahim, B., Capozucca, R., \& Wahab, M. A. (2018). Damage detection in CFRP composite beams based on vibration analysis using proper orthogonal decomposition method with radial basis functions and cuckoo search algorithm. Composite Structures, 187, 344-353.

[16]. Chen, J. F., \& Teng, J. G. (2001). Anchorage strength models for FRP and steel plates bonded to concrete. Journal of structural engineering, 127(7), 784-791.

[17]. Yuan, H., Teng, J. G., Seracino, R., Wu, Z. S., \& Yao, J. (2004). Full-range behavior of FRP-toconcrete bonded joints. Engineering structures, 26(5), 553-565.

[18]. Wu, Z., Yuan, H., \& Niu, H. (2002). Stress transfer and fracture propagation in different kinds of adhesive joints. Journal of Engineering Mechanics, 128(5), 562-573.

[19]. da Silva, L. F., das Neves, P. J., Adams, R. D., \& Spelt, J. K. (2009). Analytical models of adhesively bonded joints - Part I: Literature survey. International Journal of Adhesion and Adhesives, 29(3), 319-330.

[20]. da Silva, L. F., das Neves, P. J., Adams, R. D., Wang, A., \& Spelt, J. K. (2009). Analytical models of adhesively bonded joints-Part II: Comparative study. International Journal of Adhesion and Adhesives, 29(3), 331-341.

[21]. Ferracuti, B., Savoia, M. A. Z. Z. O. T. T. I., \& Mazzotti, C. (2007). Interface law for FRP-concrete delamination. Composite structures, 80(4), 523-531.

[22]. Grande, E., Milani, G., \& Sacco, E. (2008). Modelling and analysis of FRP-strengthened masonry panels. Engineering structures, 30(7), 1842-1860.

[23]. Ghiassi, B., Oliveira, D. V., Lourenço, P. B., \& Marcari, G. (2013). Numerical study of the role of mortar joints in the bond behavior of FRPstrengthened masonry. Composites Part B: Engineering, 46, 21-30.

[24]. Basilio, I., Fedele, R., Lourenço, P. B., \& Milani, G. (2014). Assessment of curved FRP-reinforced masonry prisms: experiments and modeling. Construction and Building Materials, 51, 492-505.

[25]. Capozucca, R., Magagnini, E., \& Vecchietti, M. V. (2020). Delamination Buckling of FRP: Experimental Tests and Theoretical Model. In Proceedings of the 13th International Conference on Damage Assessment of Structures (pp. 753-766). Springer, Singapore.

[26]. Capozucca, R., \& Magagnini, E. (2020). Experimental response of masonry walls in-plane loading strengthened with GFRP strips. Composite Structures, 235, 111735.

[27]. Capozucca, R., \& Magagnini, E. (2020). RC beam models damaged and strengthened with GFRP strips under bending loading and free vibration. Composite Structures, 253, 112730. 
[28]. Reddy, J. N., Barbero, E. J., \& Teply, J. L. (1989). A plate bending element based on a generalized laminate plate theory. International Journal for Numerical Methods in Engineering, 28(10), 2275-2292.

[29]. Barbero, E. J., \& Reddy, J. (1991). Modeling of delamination in composite laminates using a layerwise plate theory. International Journal of Solids and Structures, 28(3), 373-388.

[30]. Kardomateas, G. A., Pelegri, A. A., \& Malik, B. (1995). Growth of internal delaminations under cyclic compression in composite plates. Journal of the Mechanics and Physics of Solids, 43(6), 847-868.

[31]. Chai, H., Babcock, C. D., \& Knauss, W. G. (1981). One dimensional modelling of failure in laminated plates by delamination buckling. International Journal of Solids and Structures, 17(11), 1069-1083.

[32]. Kim, Y., Davalos, J. F., \& Barbero, E. J. (1997). Delamination buckling of FRP layer in laminated wood beams. Composite structures, 37(3-4), 311-320.

[33]. Capozucca, R. (2018). Vibration analysis of damaged RC beams strengthened with GFRP. Composite Structures, 200, 624-634.
[34]. ASTM Committee D-30 on Composite Materials. (2008). Standard test method for tensile properties of polymer matrix composite materials. ASTM International.

[35]. Benjamin, J. R., \& Williams, H. A. (1958). The behavior of one-story brick shear walls. Journal of the structural division, 84(4), 1-30.

[36]. ANSYS Inc.(2019). ANSYS manual. USA: Southpoint.

[37]. Grande, E., Milani, G., \& Sacco, E. (2008). Modelling and analysis of FRP-strengthened masonry panels. Engineering structures, 30(7), 1842-1860.

[38]. CNR-DT 200/2004.(2004). Guide for the design and construction of externally bonded FRP systems for strengthening existing structures. [In Italian]

Retrieved from: https://www.cnr.it/it/node/2619 [accessed: 10 September 2020].

[39]. Norme Tecniche per le Costruzioni (2018).. (In Italian). Retrieved from:

https://www.airesingegneria.it/site/assets/files/1128/nt c18 normetecniche.pdf

[accessed: 10 September 2020]. 